\title{
Motion analysis and fuzzy-PID control algorithm designing for the pitch angle of an underwater glider
}

\author{
Yu-hai Liu ${ }^{a}$, Zhi-qiang Su ${ }^{b}$, Xin Luan ${ }^{a}$, Da-lei Song ${ }^{b, *}$, Lei Han ${ }^{a}$ \\ ${ }^{a}$ School of Information Science and Engineering, Ocean University of China. \\ ${ }^{b}$ College of Engineering, Ocean University of China, 238 Songling Road, Qingdao, Shandong, 266100, China.
}

\begin{abstract}
Underwater gliders are used for deep-water gliding to observe large areas with minimal energy consumption. The pitch angle of the underwater glider is an important control parameter. This study involved designing a fuzzy-PID controller for the pitch angle of an underwater glider based on hydrodynamics analysis. The formula of pitch angle is obtained and a system identification method was used to identify the transfer function based on the time-domain equation and initial experimental data. The fuzzy-PID control algorithm was used to design the controller. Lake and sea trials indicated that the minimum overshoot reached $0 \%$ and the settling time was about $34 \mathrm{~s}$ when the change of the angle was $15^{\circ}$. The minimum steady-state error was $0.8^{\circ}$. These advantages could reduce the consumption of energy and improve the accuracy of gliding trajectory. Therefore, this control algorithm should be applied to control the pitch of the gliders. (C)2017 All rights reserved.
\end{abstract}

Keywords: Underwater glider, pitch angle, fuzzy-PID control, mathematical mode. 2010 MSC: 70E60, 93C42, 93C85, 97R40.

\section{Introduction}

Underwater gliders are becoming popular portable marine monitoring platforms. A glider is an autonomous underwater vehicle (AUV) that uses buoyancy changes to convert vertical motion into horizontal motion with the help of wings. A glider can move forward with less power consumption than conventional AUVs, which are usually propelled using electrically driven propellers. Therefore, a glider is a small, smart, and cost-effective ocean sampling platform with a long operational time. Widely used underwater gliders include the Seaglider [5], Spray [18], and Slocum [4, 8].

Control of the pitch angle, which is often achieved using a moveable weight such as battery packs, plays an important role in controlling glider motion. Most existing pitch control algorithms can be classified into two types: classic proportional, integral, and derivative (PID) algorithms [9]; and linear quadratic regulator (LQR) algorithms [2, 10, 12]. Some early researches used the classical PID control algorithm to control the pitch angle. However, the classical PID control algorithm cannot solve this kind of control problem well because the nature of the pitch angle control problem is nonlinear, strongly coupling, and of

\footnotetext{
*Corresponding author

Email addresses: songdalei@ouc.edu.cn (Da-lei Song), hanlei@ouc.edu.cn (Lei Han)
} 
large inertia. After the three parameters of the PID controller are determined, they cannot be adjusted in real time, leading to poor self-adaptability. Subsequently, the LQR control algorithm was developed. Generally, LQR performs better than the classical PID algorithm. It can reduce the overshoot [3] and decrease the adjustment time. LQR can not be a good solution to solve the problem due to the characteristics of the pitch angle bring. And, LQR needs to obtain more accuracy transfer function of the pitch angle, then it needs to do the Z-transform. Thus, calculation is very complex.

Some new algorithms have also been proposed. Leonard and Graver [11] derived equations of motion for underwater gliders that included buoyancy changes and a movable mass system to derive a Lyapunov function to prove the stability of the steady motions. Seo et al. [17] developed a simulation program for pitch control using computational fluid dynamics (CFD) analysis. Isa and Arshad [8] developed a neural network predictive control (NNPC) algorithm. However, it is difficult to control the pitch angle in real-time [14].

Fuzzy-PID [13] control has been used widely in industrial control. The fuzzy-PID control algorithm is a promising control method for complex nonlinear problems [1, 16, 21]. Sahu et al. [15] proposed a hybrid firefly algorithm (FA) and pattern search (PS) optimized fuzzy-PID controller for load frequency control (LFC) of multi-area power systems. Sahu et al. [16] examined a teaching-learning based optimization algorithm-based fuzzy-PID controller for automatic generation control of a multi-area power system. The fuzzy-PID control algorithm finds the relationship between three parameters $(K p, K i$, and $K d)$, error (e), and the rate of change in the error $(\Delta \mathrm{e})$ based on fuzzy math theory, the fuzzy language variable, and fuzzy logic reasoning $[6,19]$. It changes the three parameters on-line by computing e and $\Delta \mathrm{e}$ continuously, achieving better dynamic and static performance.

This study involved developing a fuzzy-PID algorithm for controlling the pitch angle. Based on fuzzy logic and fuzzy mathematics, the control algorithm can adjust the PID parameters real-time to meet the control requirements. It is suitable for the control of high order and nonlinear systems with complex inertia parts. This paper is organized as follows: Section 2 establishes the mathematical model and proposes fuzzy-PID algorithm; Section 3 describes the results of a simulation and lake/sea trials; Section 4 presents conclusions.

\section{Methods}

\subsection{Mathematical model}

\subsubsection{Body coordinates and velocity coordinates}

Three coordinate frames were used to describe the motion of an underwater glider: the inertial, body, and flow frames (Fig. 1) [20].

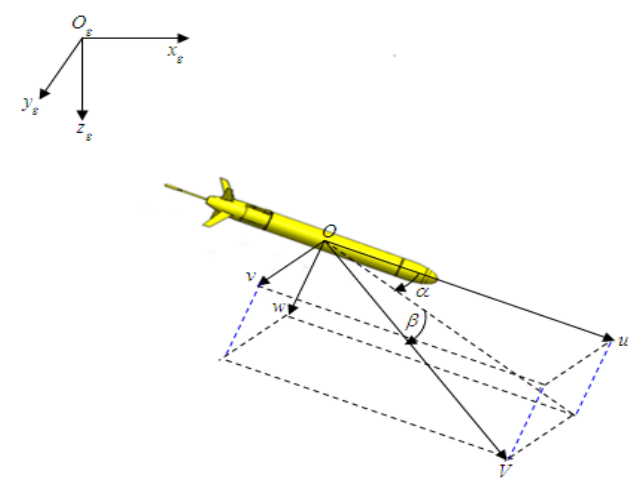

Figure 1: Underwater glider body and velocity coordinates.

Here, $\mathrm{O}$ always coincides with the origin of the coordinate system of the body; the $O x_{\mathrm{a}}$ axis is aligned along the velocity vector $\vec{V}$ of the underwater glider and points forward; the $O z_{\mathrm{a}}$ axis is the vertical axis of the body glider, and is perpendicular to the $O x_{a}$ axis and points down; and the $O y_{a}$ axis is 
perpendicular to the $O x_{\mathrm{a}} z_{\mathrm{a}}$ plane and points to the right. $\mathrm{o}_{\mathrm{g}}$ is the origin of the coordinate system of the geography; $x_{g}$ is the horizontal axis of the coordinate system of the geography paralleling the latitude; $y_{g}$ is the longitudinal axis of the coordinate system of the geography paralleling the longitude; and $z_{g}$ is the vertical axis pointing to the center of earth.

\subsubsection{The motion equation of underwater glider}

At first, we would like to introduce the parameters of underwater glider for the motion equation. The equation includes parameters, dynamic parameters, and property parameters. They are showed in Table 1.

Table 1: The parameters which we used to build the mathematical model.

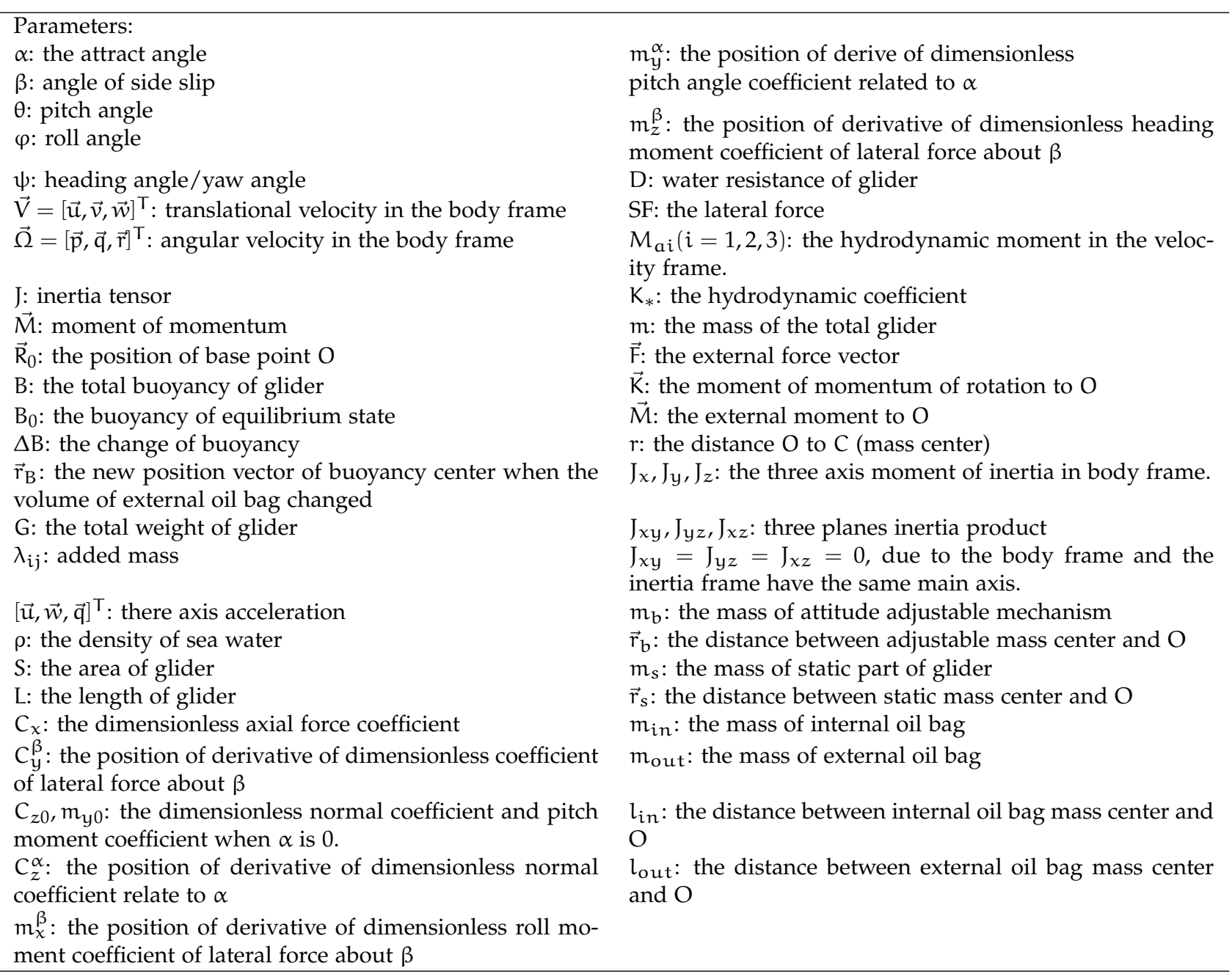

Then we must introduce what we did for obtaining the motion equation: First, according to the inertial coordinate system, the body coordinate system, and the speed coordinate system, the transformation matrix of the coordinate system was obtained. Second, according to the underwater glider translation and rotation, we built the relationship equation between displacement rate and the sailing speed in inertial coordinate system. At the same time, the relationship equation between posture angles change rate and angular velocity was also built. Thus the kinematic equations of the underwater glider was obtained. Third, the force and moment of the glider were analyzed, and the buoyancy and buoyancy moment, the gravity and the gravity moment, the hydrodynamic and the hydrodynamic moment were obtained. Fourth, the dynamic equations of the underwater glider were obtained by the force and moment analysis and Newton's law. Fifth, we combined second step with fourth step and got the motion equation of the underwater glider, as follows: 


$$
\begin{aligned}
& \mathrm{m} \cdot\left(\dot{\mathrm{u}}-v \mathrm{r}+w \mathrm{q}-\dot{\mathrm{r}} \mathrm{r}_{2}+\dot{\mathrm{q}} \mathrm{r}_{3}-\mathrm{r} \dot{\mathrm{r}}_{2}+\mathrm{q} \dot{\mathrm{r}}_{3}\right) \\
& =(B-G) \cdot \sin \theta+\left(\frac{1}{2} \rho S V^{2} C_{x}+\frac{1}{2} \rho S L V C_{x}^{q} q\right)-\left(\lambda_{11} \cdot \dot{\vec{u}}+\lambda_{33} \vec{w} \cdot \vec{q}+\lambda_{35} \vec{q}^{2}\right. \\
& \left.-\lambda_{22} \vec{v} \cdot \vec{r}+\lambda_{24} \vec{p} \cdot \vec{r}-\lambda_{26} \vec{r}^{2}\right) m \cdot\left(\dot{v}+u r-w p+\dot{r} r_{1}-\dot{p} r_{3}+r \dot{r}_{1}-p \dot{r}_{3}\right) \\
& =-(B-G) \cdot \sin \phi \cdot \cos \theta+\left(\frac{1}{2} \rho S V^{2} C_{y}^{\beta} \beta+\frac{1}{2} \rho S L V\left(C_{y}^{p} p+C_{y}^{r} r\right)\right) \\
& -\left(\lambda_{22} \cdot \dot{\vec{v}}+\lambda_{24} \cdot \dot{\vec{p}}+\lambda_{26} \cdot \dot{\vec{r}}+\lambda_{11} \vec{u} \cdot \vec{r}-\lambda_{33} \vec{w} \cdot \vec{p}-\lambda_{35} \vec{p} \cdot \vec{q}\right) \\
& \mathrm{m} \cdot\left(\dot{w}-u q+v p-\dot{q} r_{1}+\dot{p} r_{2}-q \dot{r}_{1}+p \dot{r}_{2}\right) \\
& =-(B-G) \cdot \cos \phi \cdot \cos \theta+\left(\frac{1}{2} \rho S V^{2}\left(C_{z 0}+C_{z}^{\alpha} \alpha\right)\right. \\
& \left.+\frac{1}{2} \rho \operatorname{SLVC}_{z}^{\mathrm{q}} \mathrm{q}\right)-\left(\lambda_{33} \cdot \dot{\vec{w}}+\lambda_{35} \cdot \dot{\vec{q}}+\lambda_{22} \overrightarrow{\mathrm{u}} \cdot \overrightarrow{\mathrm{p}}+\lambda_{24} \overrightarrow{\mathrm{p}}^{2}+\lambda_{26} \overrightarrow{\mathrm{p}} \cdot \overrightarrow{\mathrm{r}}-\lambda_{11} \overrightarrow{\mathrm{u}} \cdot \overrightarrow{\mathrm{q}}\right) J_{x} \cdot \dot{\mathrm{p}} \\
& +\left(\mathrm{J}_{z}-\mathrm{J}_{\mathrm{y}}\right) \cdot \mathrm{qr}+(\dot{w}+v p-u q) r_{2}-(\dot{v}+u r-w p) r_{3} \\
& =\left(\mathrm{B} \cdot \mathrm{r}_{\mathrm{B} 3}-\mathrm{G} \cdot \mathrm{r}_{\mathrm{G} 3}\right) \sin \phi \cdot \cos \theta-\left(\mathrm{B} \cdot \mathrm{r}_{\mathrm{B} 2}-\mathrm{G} \cdot \mathrm{r}_{\mathrm{G} 2}\right) \cos \phi \cdot \cos \theta \\
& +\frac{1}{2} \rho S L V^{2} m_{x}^{\beta} \beta+\frac{1}{2} \rho S L^{2} V\left(m_{x}^{p} p+m_{x}^{r} r\right)-\left(\lambda_{42} \cdot \dot{\vec{v}}+\lambda_{44} \cdot \dot{\vec{p}}+\lambda_{46} \cdot \dot{\vec{r}}+\lambda_{26} \vec{v} \cdot \vec{q}\right. \\
& +\lambda_{46} \vec{p} \cdot \vec{q}+\lambda_{66} \vec{q} \cdot \vec{r}-\lambda_{35} \vec{w} \cdot \vec{r}-\lambda_{55} \vec{q} \cdot \vec{r}+\lambda_{35} \vec{v} \cdot \vec{q}-\lambda_{24} \vec{w} \cdot \vec{p}-\lambda_{26} \vec{w} \cdot \vec{r} \\
& \left.+\left(\lambda_{33}-\lambda_{22}\right) \vec{v} \vec{w}\right) J_{y} \cdot \dot{q}+\left(J_{x}-J_{z}\right) \cdot p r+(\dot{u}+w q-v r) r_{3}-(\dot{w}+v p-u q) r \\
& =\left(B \cdot r_{B}-G \cdot r_{G 3}\right) \sin \theta+\left(B \cdot r_{B 1}-G \cdot r_{G 1}\right) \cos \phi \cdot \cos \theta+\frac{1}{2} \rho S L V^{2}\left(m_{y 0}+m_{y}^{\alpha} \alpha\right) \\
& +\frac{1}{2} \rho \mathrm{SL}^{2} \mathrm{Vm} \mathrm{m}_{\mathrm{y}}^{\mathrm{q}} \mathrm{q}-\left(\lambda_{53} \cdot \dot{\vec{w}}+\lambda_{55} \cdot \dot{\overrightarrow{\mathrm{q}}}+\lambda_{24} \vec{v} \cdot \overrightarrow{\mathrm{r}}+\lambda_{44} \overrightarrow{\mathrm{p}} \cdot \overrightarrow{\mathrm{r}}\right. \\
& +\lambda_{46} \overrightarrow{\mathrm{r}}^{2}-\lambda_{26} \vec{v} \cdot \overrightarrow{\mathrm{p}}-\lambda_{46} \overrightarrow{\mathrm{p}}^{2}-\lambda_{66} \overrightarrow{\mathrm{p}} \cdot \overrightarrow{\mathrm{r}} \\
& \left.-\lambda_{35} \vec{u} \cdot \vec{q}+\left(\lambda_{11}-\lambda_{33}\right) \vec{u} \vec{w}\right) J_{z} \cdot \dot{r}+\left(J_{y}-J_{x}\right) \cdot p q+(\dot{v}+u r-w p) r_{1}-(\dot{u}+w q-v r) r_{2} \\
& =-\left(B \cdot r_{B 2}-G \cdot r_{G 2}\right) \sin \theta-\left(B \cdot r_{B 1}-G \cdot r_{G 1}\right) \sin \phi \cdot \cos \theta+\frac{1}{2} \rho S L V^{2} m_{z}^{\beta} \beta \\
& +\frac{1}{2} \rho S L^{2} \mathrm{~V}\left(\mathrm{~m}_{z}^{\mathrm{p}} \mathrm{p}+\mathrm{m}_{z}^{\mathrm{r}} \mathrm{r}\right)-\left(\lambda_{62} \cdot \dot{\vec{v}}+\lambda_{64} \cdot \dot{\overrightarrow{\mathrm{p}}}+\lambda_{66} \cdot \dot{\overrightarrow{\mathrm{r}}}+\lambda_{35} \overrightarrow{\mathrm{w}} \cdot \overrightarrow{\mathrm{p}}+\lambda_{55} \overrightarrow{\mathrm{p}} \cdot \overrightarrow{\mathrm{q}}-\lambda_{24} \overrightarrow{\mathrm{v}} \cdot \overrightarrow{\mathrm{q}}\right. \\
& \left.-\lambda_{44} \vec{p} \cdot \vec{q}-\lambda_{64} \vec{q} \cdot \vec{r}+\lambda_{24} \vec{u} \cdot \vec{p}+\lambda_{26} \vec{u} \cdot \vec{r}+\left(\lambda_{11}-\lambda_{22}\right) \vec{u} \vec{v}\right),
\end{aligned}
$$

$$
\left\{\begin{aligned}
\dot{x}_{g}= & \cos \theta \cdot \cos \psi \cdot u+(\sin \phi \cdot \sin \theta \cdot \cos \psi-\cos \phi \cdot \sin \psi) \cdot v \\
& +(\cos \phi \cdot \sin \theta \cdot \cos \psi+\sin \phi \cdot \sin \psi) \cdot w, \\
\dot{y}_{g}= & \cos \theta \cdot \sin \psi \cdot u+(\sin \phi \cdot \sin \theta \cdot \sin \psi+\cos \phi \cdot \cos \psi) \cdot v \\
& +(\cos \phi \cdot \sin \theta \cdot \sin \psi-\sin \phi \cdot \cos \psi) \cdot w, \\
\dot{z}_{g}= & -\sin \theta \cdot u+\sin \phi \cdot \cos \theta \cdot v+\cos \phi \cdot \cos \theta \cdot w, \\
p= & \dot{\phi}-\dot{\psi} \cdot \sin \theta, \\
\mathrm{q}= & \dot{\theta} \cdot \cos \phi+\dot{\psi} \cdot \sin \phi \cdot \cos \theta, \\
r= & -\dot{\theta} \cdot \sin \phi+\dot{\psi} \cdot \cos \phi \cdot \cos \theta .
\end{aligned}\right.
$$

Based on the position relationship between the body coordinate system and the velocity coordinate system, the following equation was added to the motion equation of the underwater glider:

$$
\left\{\begin{aligned}
V^{2} & =u^{2}+v^{2}+w^{2}, \\
\tan \alpha & =\frac{w}{u} \\
\sin \beta & =\frac{v}{v} .
\end{aligned}\right.
$$




\subsubsection{Pitch angle equation}

Because the main purpose of this study is to analyze the pitch angle, the main focus is analyzing the vertical motion of the glider.

It is necessary to decompose the motion of the glider into vertical and lateral movement. This reduces the degrees of freedom (DOF) from six to three, thereby reducing the difficulty of the movement analysis. Because the deviation of the movement of the underwater glider from vertical symmetry is negligibly small, it is possible to separate the vertical movement from the six DOF motion. When developing an equation for the pitch angle, it is important to conduct kinetic analysis in the diving and floating states to derive the mathematical models.

An underwater glider in the vertical plane is affected mainly by gravity (G), hydrodynamics (D), buoyancy (F), and resistance (Fig. 2). Here, $\theta$ is the pitch angle, $\alpha$ is the angle of attack, and $\tau$ is the gliding angle.

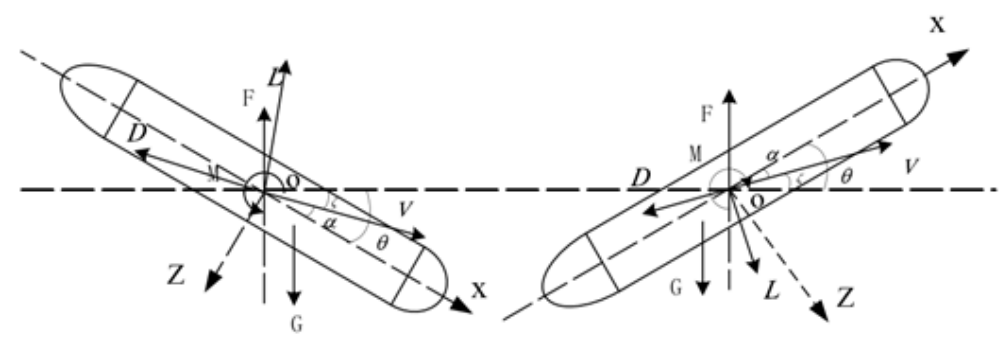

Figure 2: Kinetic analysis of the underwater glider diving and floating in the vertical plane.

At first, we simplified the space motion equation of underwater glider based on vector matrix method in the vertical plane at Subsection 2.1.2, the motion parameters meet:

$$
\left(\vec{V}_{\mathrm{O}}\right)_{\mathrm{b}}=\left[\begin{array}{c}
\mathrm{u} \\
0 \\
w
\end{array}\right], \quad(\vec{\Omega})_{\mathrm{b}}=\left[\begin{array}{c}
0 \\
\vec{q} \\
0
\end{array}\right], \quad(\overrightarrow{\mathrm{r}})_{\mathrm{b}}=\left[\begin{array}{c}
\mathrm{r}_{1} \\
0 \\
\mathrm{r}_{3}
\end{array}\right], \quad \text { Euler }=\left[\begin{array}{l}
0 \\
\theta \\
0
\end{array}\right] .
$$

Based on it, the viscous dynamic model was simplified by Lenord's (Leonard and Graver. 2011) vertical surface model. The inertial hydrodynamic force was only reserved for the additional mass. The equations of motion could be simplified to:

$$
\begin{aligned}
& \dot{u}=\frac{1}{m+\lambda_{11}}\left((B-G) \sin \theta-D \cos \alpha+L \sin \alpha-\lambda_{35} q^{2}-m r_{3} \dot{q}-\left(m+\lambda_{33}\right) w q\right), \\
& \dot{w}=\frac{1}{m+\lambda_{33}}\left(-(B-G) \cos \theta+D \sin \alpha-L \cos \alpha+\left(m+\lambda_{11}\right) u q-\lambda_{35} \dot{q}+m r_{1} \dot{q}+m \dot{r}_{1} q\right), \\
& \dot{\mathrm{q}}=\frac{1}{\mathrm{~J}_{\mathrm{y}}+\lambda_{55}}\left(-\mathrm{G} \cdot \mathrm{r}_{3} \cdot \sin \theta+\left(\mathrm{B} \cdot \mathrm{r}_{\mathrm{B} 1}-\mathrm{G} \cdot \mathrm{r}_{1}\right) \cdot \cos \theta+\mathrm{M}_{\mathrm{a} 2}\right. \\
& -\left(\lambda_{53} \cdot \dot{w}-\lambda_{35} u \cdot q+\left(\lambda_{11}-\lambda_{33}\right) u w-m r_{3}(\dot{u}+w q)+m r_{1}(\dot{w}-u q)\right), \\
& \dot{x}_{\mathrm{g}}=\cos \theta \cdot u+\cdot \sin \theta \cdot w \text {, } \\
& \dot{z}_{\mathrm{g}}=-\sin \theta \cdot u+\cos \theta \cdot w \text {, } \\
& \mathrm{q}=\dot{\theta}, \\
& \tan \alpha=-\frac{w}{u}, \\
& \mathrm{~V}^{2}=\mathrm{u}^{2}+w^{2}, \\
& \mathrm{D}=\left(\mathrm{K}_{\mathrm{D} 0}+\mathrm{K}_{\mathrm{D}} \alpha^{2}\right) \mathrm{V}^{2} \text {, } \\
& \mathrm{L}=\left(\mathrm{K}_{\mathrm{L} 0}+\mathrm{K}_{\mathrm{L}} \alpha\right) \mathrm{V}^{2} \text {, } \\
& M_{\mathrm{a} 2}=\left(K_{M 0}+K_{M 2} \alpha\right) V^{2}+K_{\Omega 2} q \text {. }
\end{aligned}
$$


Here, $u, w$, and $q$ were the three-dimensional angular velocities and $q$ was the angular velocity in the vertical plane, $\theta$ was the pitch angle, $\alpha$ was the angle of attack, $V$ was the velocity vector, and $K, L, M$, and $D$ were hydrodynamic coefficients. We distilled the formula " $q=\dot{\theta}$ ", and substituted the rest formulas of (2.1) into the formula " $q=\dot{\theta}$ ", the following equation was obtained:

$$
\begin{aligned}
\ddot{\theta}= & \frac{1}{J y+\lambda_{35}}\left\{\left[-G_{3}+\frac{m r_{3}}{m+\lambda_{11}}(B-G)\right] \sin \theta+\left[B r_{B 1}-\left(G+\frac{m}{m+\lambda_{33}}\right)(G-B)\right] r_{1} \cos \theta\right. \\
& +\left(K_{M 0}+K_{M 2} \alpha\right) V^{2}+K_{\Omega 2} \int \theta d t+\left[\frac{-\lambda_{53}\left(K_{D 0}+K_{D} \alpha^{2}\right) V^{2}}{m+\lambda_{33}}+\frac{m r_{3}\left(K_{L 0}+K_{L} \alpha\right) V^{2}}{m+\lambda_{11}}\right. \\
& \left.-\frac{m\left(K_{D 0}+K_{D} \alpha^{2}\right) V^{2}}{m+\lambda_{33}}\right] \sin \alpha+\left[\frac{\lambda_{53}\left(K_{L 0}+K_{L} \alpha\right) V^{2}}{m+\lambda_{33}}-\frac{m r_{3}\left(K_{D 0}+K_{D} \alpha^{2}\right) V^{2}}{m+\lambda_{11}}\right] \cos \alpha \\
& +\frac{m\left(K_{L 0}+K_{L} \alpha\right) V^{2} \cos \alpha}{m+\lambda_{33}} r_{1}+\frac{m \lambda_{35}-m \lambda_{53}}{m+\lambda_{33}} r_{1} \theta+\left(\frac{\lambda_{35} \lambda_{53}}{m+\lambda_{33}}-\frac{m^{2} r_{3}^{2}}{m+\lambda_{33}}-\frac{m^{2} r_{1}^{2}}{m+\lambda_{33}}\right) \theta \\
& \left.-\left(m r_{1}+m^{2} r_{1} r_{1}\right) \int \theta d t\right\} .
\end{aligned}
$$

This equation could be used as a control system equation in the time domain such that the distance the battery pack moves was the equation input and the pitch angle was the output. A Laplace transformation would be required to get the transfer function for the control system in the frequency domain in order to study the system further. However, a Laplace transformation was not feasible for a complex equation in the time domain. Therefore, other methods were required to obtain the transfer function for the control system.

\subsubsection{Transfer function for the pitch angle}

The data obtained from the initial experiments examining the pitch angle can be applied to derive the transfer function, using the system identification method [7]. First, the experimental data were imported into the system identification tool box in MATLAB. The most reasonable equation was then selected to match the data line. Finally, these equation parameters were confirmed and the transfer function was obtained.

1. Importing multi-groups test data:

In order to identify the high reliability of the pitch motion control transfer function, based on different angles, the pitch angle value was recorded. After the data was converted into .mat file, then we ran the system identification toolbox, the data of each group was called and it was shown in Fig. 3.

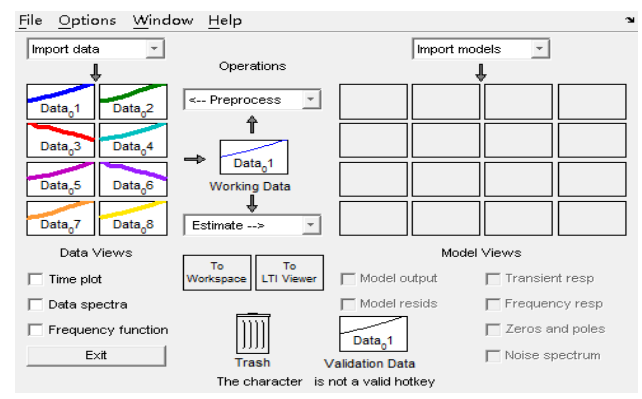

Figure 3: The test data was imported into system identification toolbox.

2. Choosing the transfer function model based on the motion model and data:

In the paper, the model of the underwater glider motion was analyzed, and the pitch angle control system had the lag phase and the system order was at least two without considering the coupling characteristics 
of the underwater glider. Combined with the pitch angle data which was imported into the toolbox, we knew the system was under-damped system. Based on the above analysis, we chose second-order under-damped lag system (a), three-order under-damped lag system with integral (b), three-order underdamped lag system (c), and the second-order under-damped lag system with integral (d) to identify the transfer function, and the matching degree was shown in Fig. 4.

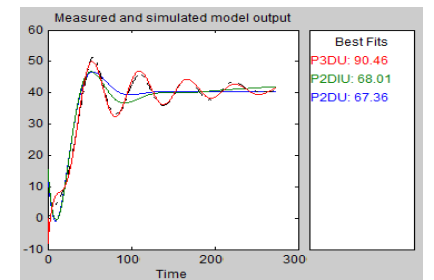

(a) the first identification results.

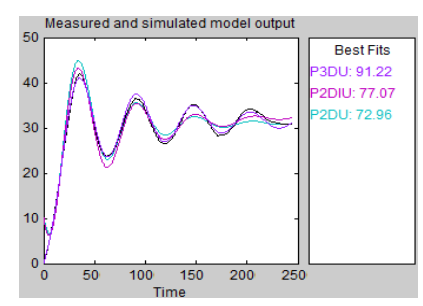

(c) the third identification results.

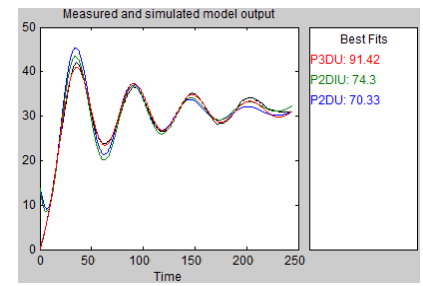

(b) the second identification results.

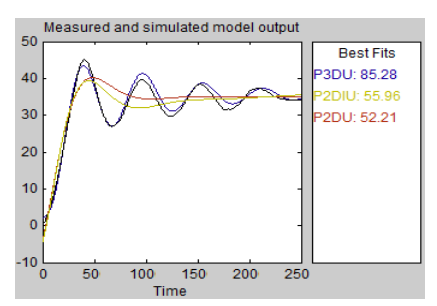

(d) the fourth identification results.

Figure 4: The model identification matching degree.

3. Choosing the optimal identification parameters:

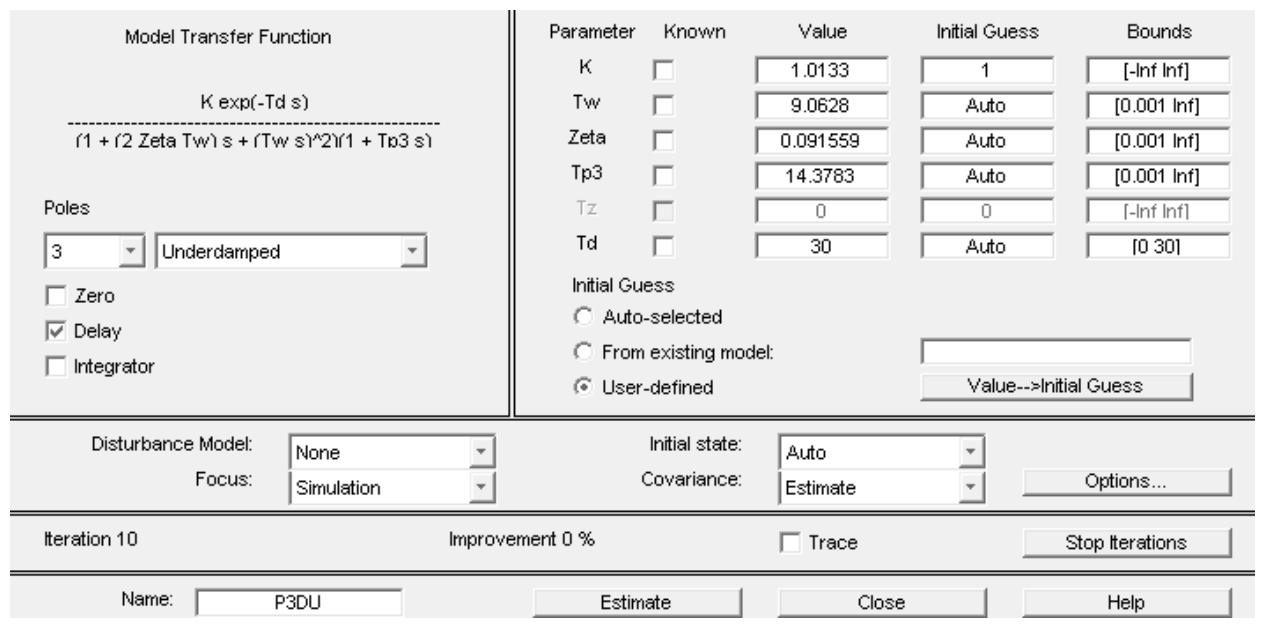

Figure 5: The three-order under-damped lag system identification parameters.

According to the analysis of model identification results and model identification matching degree, we knew the three-order under-damped lag system was the best model. Thus, we chose this model as the transfer function of pitch angle. Then we used different data to test the transfer function. Fig. 5 showed the three-order under-damped lag system identification parameters. Table 1 gave a group of the system identification results of structure parameters and it included the matching rate and weight.

At first, we want to explain the parameters $\mathrm{K}$, Tw, Zeta, Tp3, and Td. K was the coeffcient of proportionality. Tw was the two order integral coefficient. Zeta and Tp3 were the first order integral coefficient. Td was the first order differential coefficient. Therefore, the transfer function of the control of the pitch 
angle of the gliding motion of the underwater glider system based on the simplified model and system identification was obtained:

$$
\mathrm{G}(\mathrm{s})=\frac{1.0008 \mathrm{e}^{-30 \mathrm{~s}}}{\left(1+1.8243 \mathrm{~s}+81.8717 \mathrm{~s}^{2}\right)(1+12.5557 \mathrm{~s})}
$$

Table 2: The system identification parameters of pitch control system.

\begin{tabular}{ccccccc}
\hline \multirow{2}{*}{ Group } & \multirow{2}{*}{ Para } & Tw & Zeta & Tp3 & \multirow{2}{*}{ Td } & Match rate \\
\cline { 1 - 6 } No.1 & 1.0133 & 9.0628 & 0.091559 & 14.3783 & 30 & $9046 \%$ \\
No.2 & 1.0112 & 8.9346 & 0.107654 & 11.3031 & 30 & $9142 \%$ \\
No.3 & 0.9978 & 9.1018 & 0.103547 & 12.5639 & 30 & $9122 \%$ \\
No.4 & 1.0096 & 9.0977 & 0.100352 & 11.9563 & 30 & $8528 \%$ \\
Weight & 1.0080 & 9.0483 & 0.100808 & 12.5557 & 30 & \\
\hline
\end{tabular}

\subsection{Control algorithm}

\subsubsection{Control targets and proposed control algorithm}

The maximum overshoot and oscillation times reflect the transient response of the control system. The settling time indicates how long the system transition processing takes, reflecting the overall system respond. The steady-state error is a measure of the system stability index. Based on the above analysis combined with our experimental data in earlier period (Fig. 6), the following control indexes were developed: overshoot $<3^{\circ}$, steady-state error range from $-2^{\circ}$ to $2^{\circ}$, and settling time $<60$ s (Angle change is $30^{\circ}$ ).

Classic PID control is traditional feedback control. Because the pitch angle of the glider has hysteresis, and non-linear and higher-order resistance, which increase the difficulty adjusting the proportional $(\mathrm{Kp})$, integral $(K i)$, and differential $(K d)$ gain, classic PID control cannot meet the requirements. Therefore, a fuzzy PID control algorithm was designed to tune the PID controller parameters.
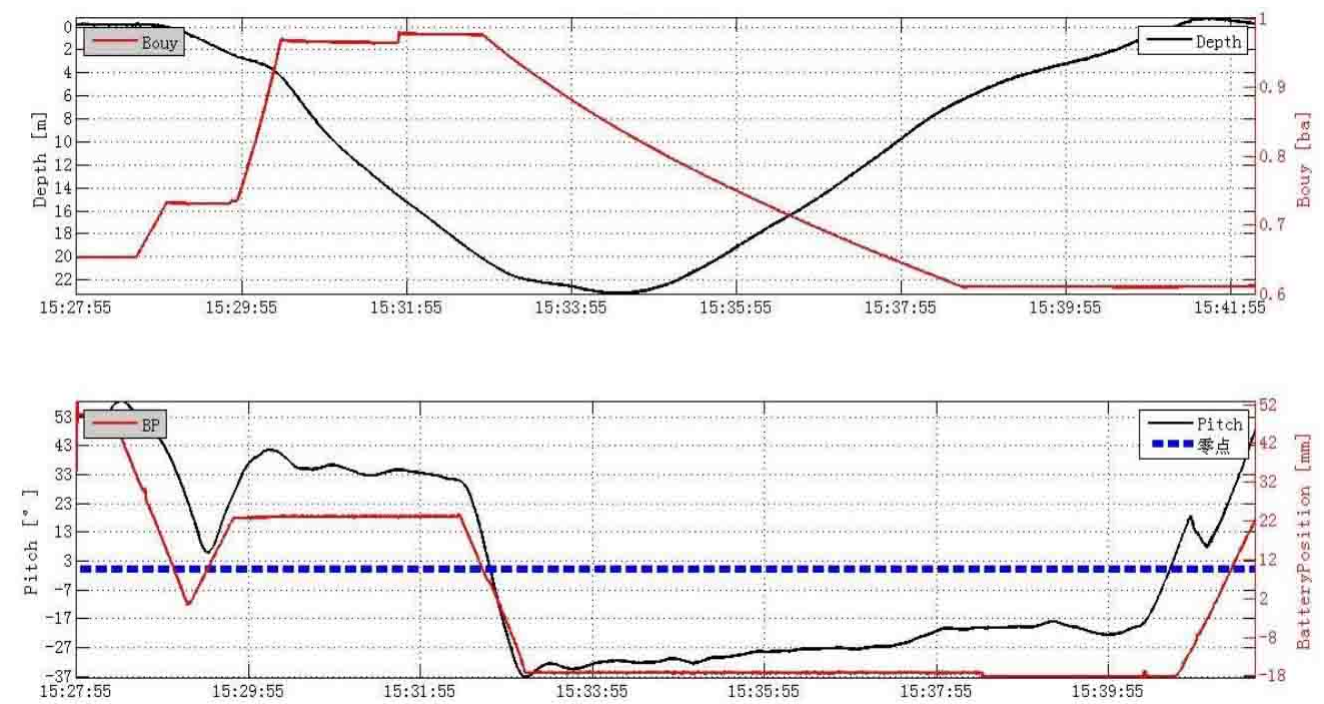

Figure 6: This was the data of depth and pitch in earlier period (2014.5.20, Qian Dao Lake in ZheJiang Province of China) with PID control algorithm. The red line represented the buoyancy and the black line represented the depth in the first picture. In the second picture, the red line represented the position of battery. From the second picture, we knew that the pitch angle did not get good control results. The maximum overshoot was about $10^{\circ}$ and the minimum steady-error was $3.4^{\circ}$. Then there were no steady-state during the floating time. 


\subsubsection{Establishing the fuzzy-PID controller}

First, fuzzy rules and membership functions were established, and a 0.05 dead band and 0.1 saturation region was designed based on the performance. The sampling period was 0.01s. The fuzzy PID control system ran in a different state, based on $K p, K i$, and $K d$. The control system inputs were the error and the rate of change in the error. The corresponding language variables take seven fuzzy values ([NB, NM, NS, ZE, PS, PM, PB]). Then, $K p, K i$, and $K d$ were selected as the output language variables (membership function). The corresponding language variables also take seven fuzzy values ([NB, NM, NS, ZE, PS, PM, $\mathrm{PB}]$ ) (Fig. 7). Finally, calculations revealed that the error factor was 3, the factor for the error change rate was 1 , and the output scale factor was 0.4. Then, $\Delta K p, \Delta K i$, and $\Delta K d$ were listed as the basis of the fuzzy rules. At last, if we wanted to use this control algorithm, we must use $C$ language to complete the code of fuzzy-PID controller, and then downloaded to the CPU.

\begin{tabular}{|c|c|c|c|c|c|c|c|}
\hline Akd & \multirow{2}{*}{$\mathrm{e}_{\mathrm{NB}}$} & \multirow{2}{*}{$\mathrm{NM}$} & $\mathrm{N}$ & \multirow{2}{*}{ ZE } & \multirow{2}{*}{ PS } & \multirow{2}{*}{ PM } & PB \\
\hline NB & NM & NM & NB & NB & NB & NM & NM \\
\hline NM & NS & NS & NM & NB & NM & NS & NS \\
\hline NS & ZE & ZE & NS & NM & NS & ZE & ZE \\
\hline ZE & PM & PM & PS & ZE & PS & PM & PM \\
\hline PS & PM & PS & ZE & NS & NM & NS & NM \\
\hline PM & NS & PS & NS & NS & NS & NS & NB \\
\hline PB & NB & NM & NM & NS & NS & NM & NB \\
\hline
\end{tabular}

(a)

\begin{tabular}{|c|c|c|c|c|c|c|c|}
\hline Akp & NB & NM & NS & ZE & PS & PM & PB \\
\hline NB & PB & PB & PM & PM & PS & ZE & ZE \\
\hline NM & PB & PB & PM & PS & Ps & ZE & NS \\
\hline NS & PM & PM & PM & PS & ZE & NS & NS \\
\hline ZE & PM & PM & PS & ZE & NS & NM & NM \\
\hline PS & PS & PS & ZE & NS & NS & NM & NM \\
\hline PM & PS & ZE & NS & NM & NM & NM & NB \\
\hline PB & ZE & ZE & NM & NM & NM & NB & NB \\
\hline
\end{tabular}

(b)

\begin{tabular}{|c|c|c|c|c|c|c|c|}
\hline$\Delta$ Nki $^{\text {C C }}$ & NB & NM & NS & ZE & PS & PM & PB \\
\hline NB & NS & NS & NS & NS & NM & NM & NM \\
\hline NM & PS & P & PS & PS & ZE & ZE & ZE \\
\hline NS & NS & NS & NS & NS & NM & NM & NM \\
\hline ZE & NB & NB & NB & NM & NB & NB & NB \\
\hline PS & ZE & NS & NS & NS & NM & NM & NB \\
\hline PM & ZE & ZE & NS & NS & NM & NB & NB \\
\hline PB & ZE & ZE & NS & NM & NM & NB & NB \\
\hline
\end{tabular}

(c)

Figure 7: The rule base of (a) $\Delta K p$, (b) $\Delta K i$, and (c) $\Delta K d$ for the fuzzy-PID control algorithm.

Pitch angle adjustment was made up of four parts. First, comparing the set value with the current value of pitch angle, duty ratio of PWM control signal was gained by calculation of pitch preprocessor. Second, motor control voltage could be obtained through the power manager. Third, electronic speed regulator controlled the speed of the motor by the voltage signal. Finally, pitch angle changed as a result of hydrodynamic effect (Fig. 8).

Pitch angle preprocessor contained the pitch angle control dead area processing, and the judgment of the proportional gain and control upper and lower limits.

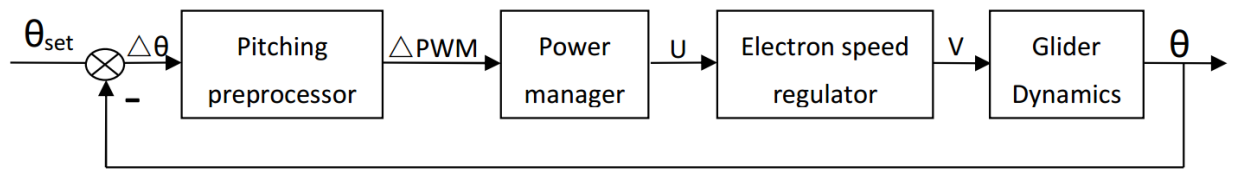

Figure 8: Pitch controller block diagram.

Based on the above analysis and fuzzy rules, the controller was designed in MATLAB/Simulink. A single closed-loop fuzzy control system was built (Fig. 9). The system input was the set value of the pitch angle and the actual control of the pitch angle was the simulation output. The step signal could be used as a set value.

\section{Results}

\subsection{Simulation results}

Simulation using MATLAB provided a Mamdani model of fuzzy control, as well as cloud charts of the proportional, integral, and differential gain.

The Mamdani model (Fig. 10 (a)) was a two-input, three-output model. The inputs were the error and rate of change of the error, while the proportional, integral, and differential gains were outputs. Fig. 10 (b) showed the proportional gain contours where the $x$-axis was the error ( -6 to 6$)$, the $y$-axis was the rate of change of the error ( -3 to 3$)$, and the $z$-axis is the proportional gain (0 to 6). Similarly, Fig. 10 (c) 


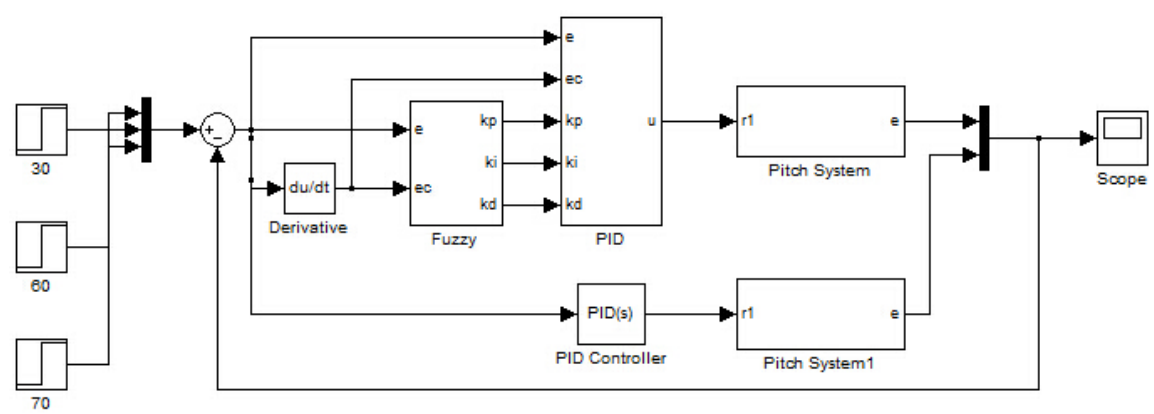

Figure 9: Schematic diagram of the fuzzy-PID control system simulation block, which includes a feedback loop and four main parts: input signal, controller, transfer function, and output display. We also used the classical PID to compare with the fuzzy-PID in the simulation. The set values were $30^{\circ}, 60^{\circ}$ (which also were the actual experiment set values) and $70^{\circ}$ (to test the adaptability about big angle).

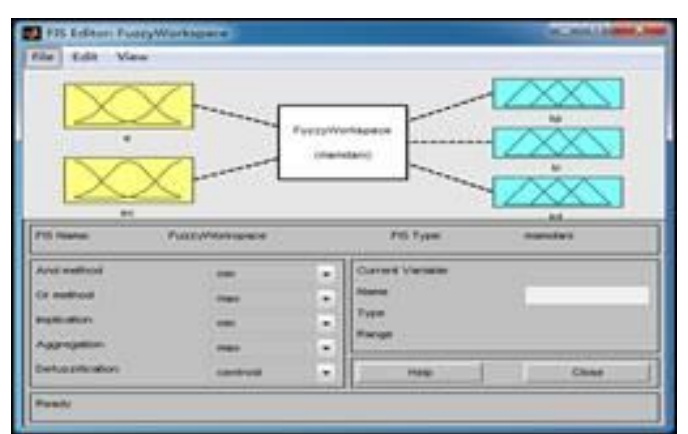

(a)

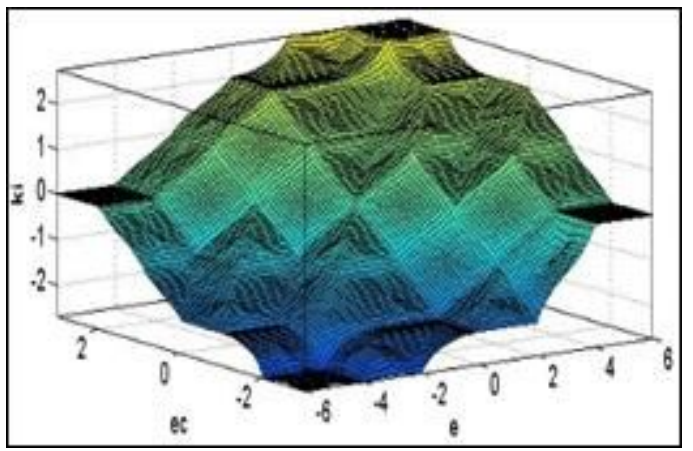

(c)

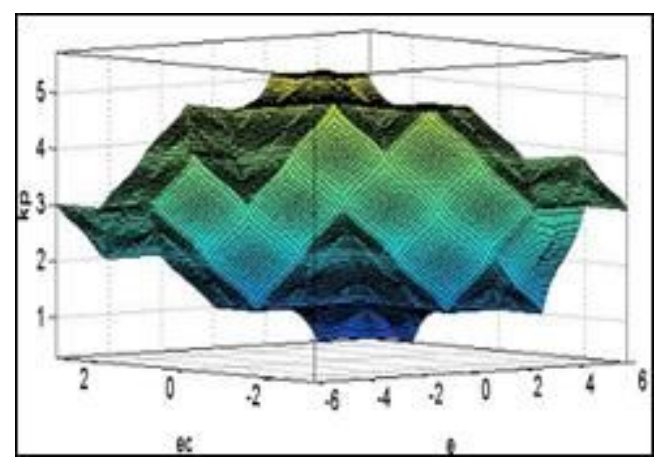

(b)

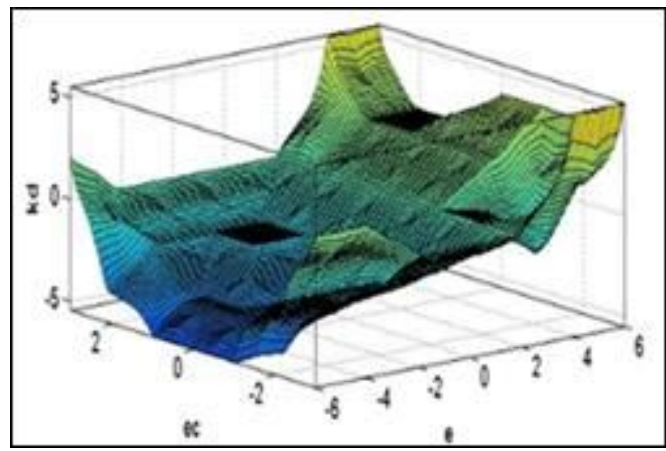

(d)

Figure 10: The simulation of the fuzzy-PID control system included: (a) the Mamdani model of fuzzy control, and (b) proportional, (c) differential, and (d) integral gains.

showed the integral gain contours where the $x$-axis was the error ( -6 to 6$)$, the $y$-axis is the rate of change of the error ( -3 to 3$)$, and the $z$-axis was the integral gain ( -3 to 3$)$. Fig. 10 (d) showed the differential gain contours where the $x$-axis was the error ( -6 to 6$)$, the $y$-axis was the rate of change of the error $(-3$ to 3 ), and the $z$-axis was the differential gain ( -3 to 3 ).

From the dynamic response curve in Fig. 11, the initial value was $0^{\circ}$ and the set value was $30^{\circ}, 60^{\circ}$ and $70^{\circ}$. Using a single close-loop control system with PID control algorithm, the system output overshoot was large (about 10\% to each of set value), and the maximum settling time was about $35 \mathrm{~s}$ when the set value was $70^{\circ}$. The dynamic response performance needed to be improved. With the fuzzy-PID control method, the pitch angle had no overshoot, there was no steady-state error, and the maximum settling time was about $25 \mathrm{~s}$ when the set value was $70^{\circ}$. Fuzzy-PID achieved better control than PID. 


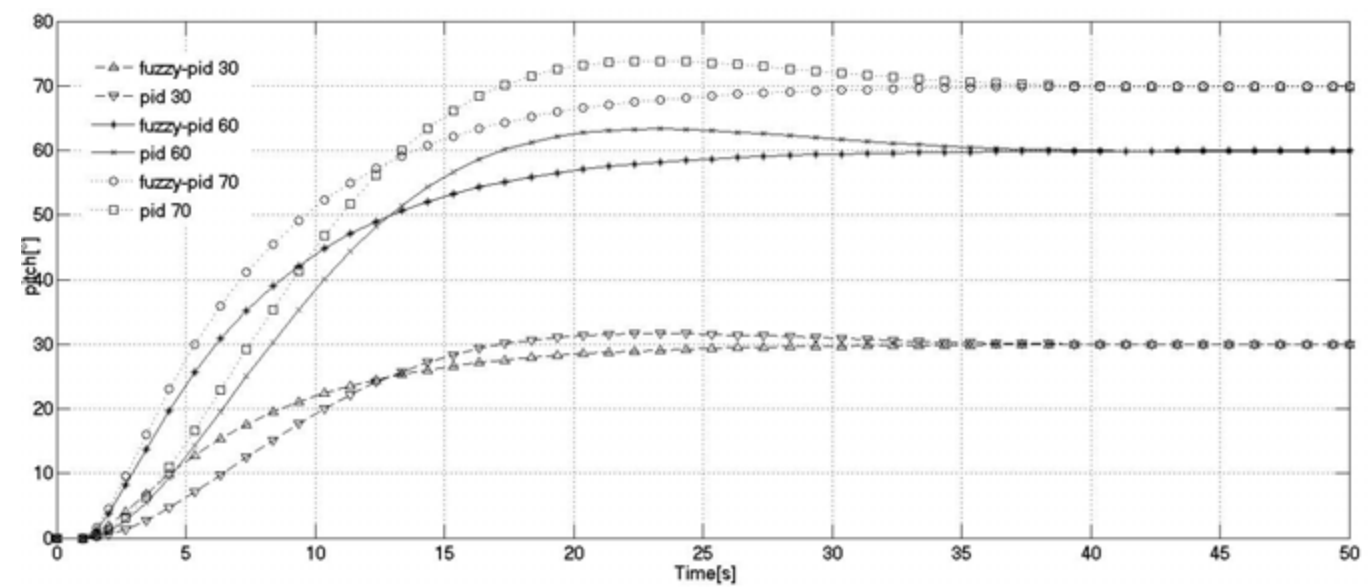

Figure 11: Simulation of the pitch angle, showing the classic PID and fuzzy-PID control results.

\subsection{Experimental results}

At first, we would like to introduce our glider, OUC-I. Table 3 and Fig. 12 showed the parameters and actual glider.

Table 3: The parameters of glider.

\begin{tabular}{|l|l|}
\hline Characteristic & Value \\
\hline Length, $L$ & $3.2 \mathrm{~m}$ \\
\hline Body diameter, $d$ & $0.25 \mathrm{~m}$ \\
\hline Horizontal wing length, $W_{H L}$ & $0.8 \mathrm{~m}$ \\
\hline Horizontal Wing width, $W_{h w}$ & $0.2 \mathrm{~m}$ \\
\hline Vertical wing length, $W_{V L}$ & $0.4 \mathrm{~m}$ \\
\hline Vertical Wing width, $W_{V w}$ & $0.2 \mathrm{~m}$ \\
\hline Hull mass, $m_{k}$ & $24.256 \mathrm{~kg}$ \\
\hline Ballast mass, $m_{b}$ & $0-2.325 \mathrm{~kg}$ \\
\hline Sliding mass(battery), $m_{s}$ & $10.734 \mathrm{~kg}$ \\
\hline Sea Water density, $\rho$ & $1023 \mathrm{~kg} / \mathrm{m}^{3}$ \\
\hline Total mass, $m_{s}$ & $77.348 \mathrm{~kg}$ \\
\hline
\end{tabular}

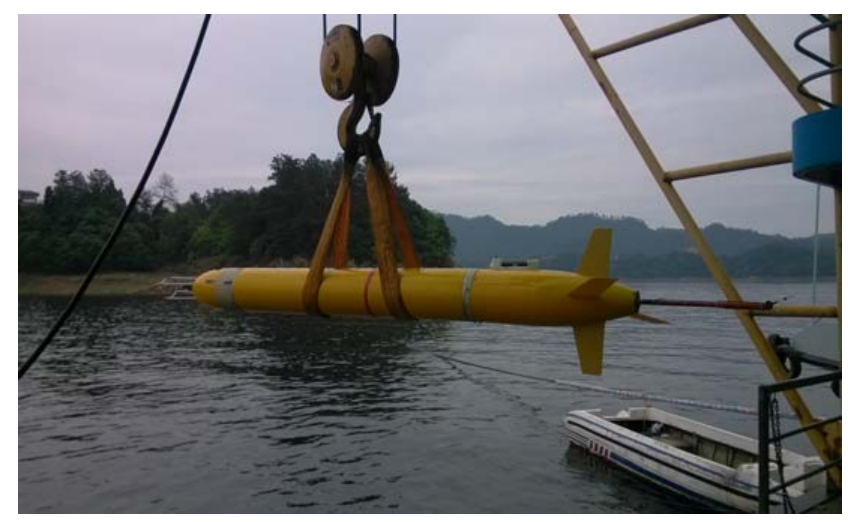

Figure 12: The glider was deploying in Qing Jiang lake trials.

\subsubsection{Qing Jiang lake trial}

In March 2015, a lake trial was conducted in Qing Jiang lake $\left(111^{\circ} 11.95^{\prime}, 30^{\circ} 42.05^{\prime} \mathrm{N}\right)$ in $\mathrm{Hu}$ Bei Province, China. This lake was very suitable for glider to test with the average depth of $87.6 \mathrm{~m}$. And the area of the lake was $256000 \mathrm{~m}^{2}$ with the current about $0.5 \mathrm{~m} / \mathrm{s}$. We deployed the glider from the main ship and sent commands to it to finish the profile gliding. Each of the profiles with the maximum depth about $100 \mathrm{~m}$ (set depth was $80 \mathrm{~m}$ ) needed $20 \mathrm{~min}$. It yielded the control results for the pitch angle shown in Fig. 13.

The glider completed three profiles with the maximum depth of $100 \mathrm{~m}$. At first, we would like to introduce our control strategy. When the current value was bigger than the set value by $15^{\circ}$, the controller would control the motor to move the battery to adjust pitch angle for 10s and the next adjustment would be after 10s to save the power. We used the KELLER pressure sensor and CTD (Conductivity, Temperature, and Depth) to test the depth and they could be accurate to $0.1 \mathrm{~m}$. The MTi-G attitude sensor was used to test the Euler angle and it could be accurate to $0.1^{\circ}$. Analysis of three of them revealed that the control indexes were reached. The three groups set values were all $30^{\circ}\left(-30^{\circ}\right.$ at diving into water and $30^{\circ}$ at floating out of water). We obtained the average steady-error was $1.4^{\circ}$, the average settling time was $34.3 \mathrm{~s}$ and there was no overshoot by synthesizing the three group data. Then we found the buoyancy had effect on pitch angle obviously. Therefore we changed our control strategy in sea trials. 
Groupl:

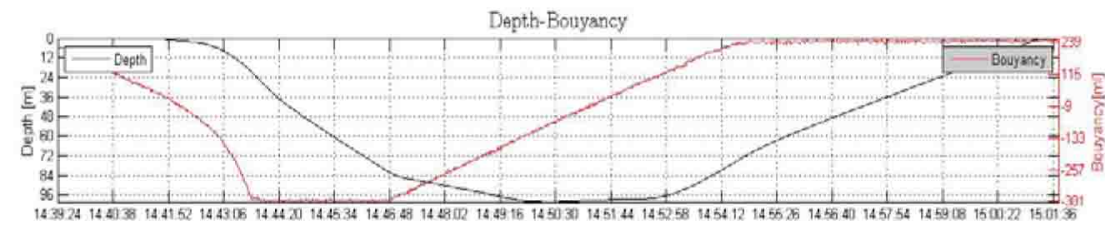

Pitch-P/AD

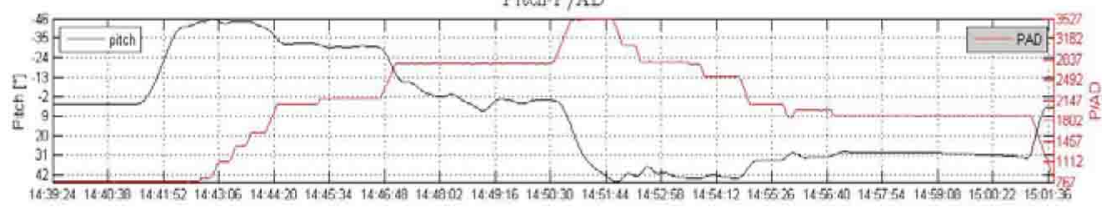

Group2:
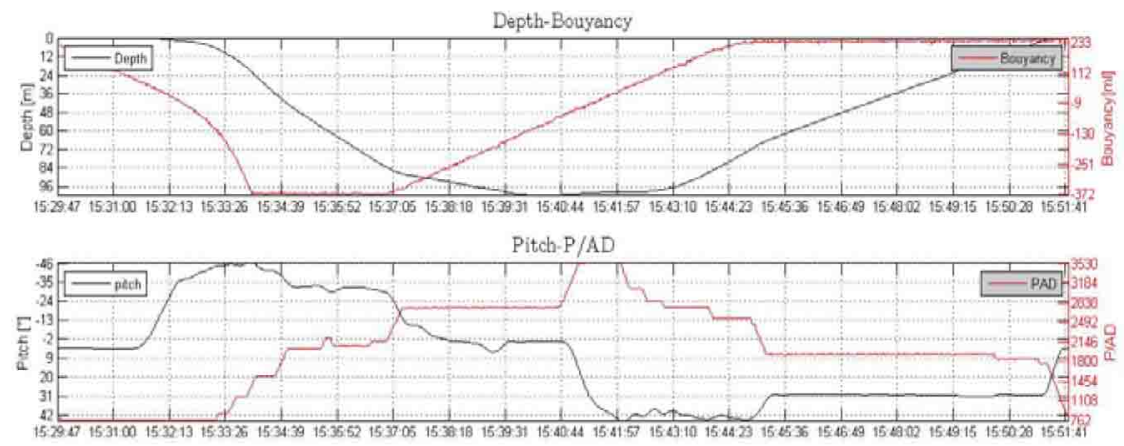

Group3:
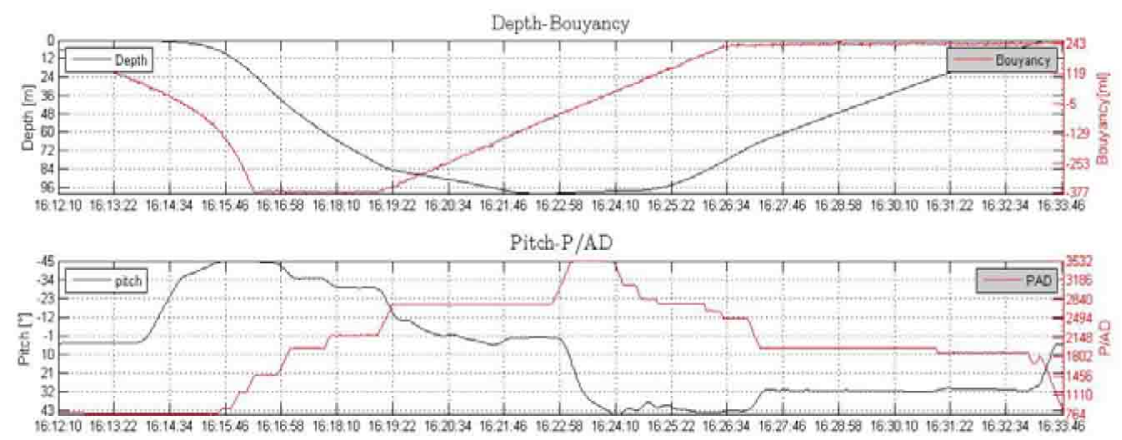

Figure 13: Three groups of the pitch angle and depth figures of the glider in the Qing Jiang lake trial.

\subsubsection{The South China Sea trial}

In April 2015, a sea trial was conducted in the South China Sea. We chose a rectangular area $\left(\mathrm{S} 1: 119^{\circ} 08.33^{\prime} \mathrm{E}, 21^{\circ} 40.62^{\prime} \mathrm{N}\right.$; S2:118 $39.49^{\prime} \mathrm{E}, 2^{\circ} 27.34^{\prime} \mathrm{N}$; S3:118 $51.72^{\prime} \mathrm{E}, 21^{\circ} 11.02^{\prime} \mathrm{N} ; \quad \mathrm{S} 4: 119^{\circ} 21.19^{\prime} \mathrm{E}$, $21^{\circ} 24.49^{\prime} \mathrm{N}$ ) as the experimental area with the average depth about $2000 \mathrm{~m}$. And the wave of the sea was $1.2 \mathrm{~m}$ with the current about $1.1 \mathrm{~m} / \mathrm{s}$. We deployed the glider from the main ship and sent commands to it to finish the profile gliding. We finished only two profiles due to the limit of time. Each of the profiles with the maximum depth about $500 \mathrm{~m}$ (set value was $500 \mathrm{~m}$ or $450 \mathrm{~m}$ ) needed $110 \mathrm{~min}$.

We changed the control strategy to weaken the buoyancy effect. We controlled the motor to adjust the battery all the time during the profile gliding to obtain the good control results.This was the difference with the lake trial. Fig. 14 showed the experiment scene of the sea trail. 


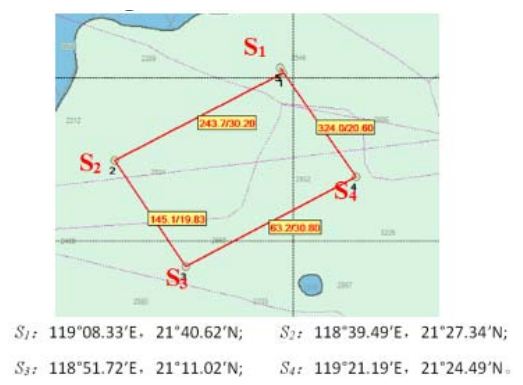

(a)

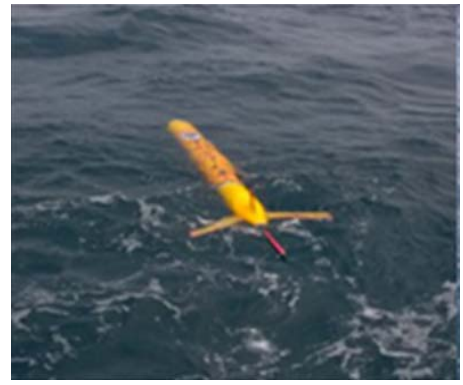

(b)

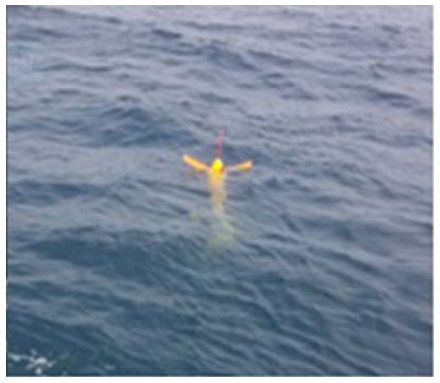

(c)

Figure 14: Underwater gilder OUC-I in the South China Sea: (a) the area of experiment in South China Sea (b) equilibrium sate and (c) communication state.

After finishing the sea trial, we sorted out the data of sea trial. It yielded the control results for the pitch angle shown in Fig. 15.

Group 1:

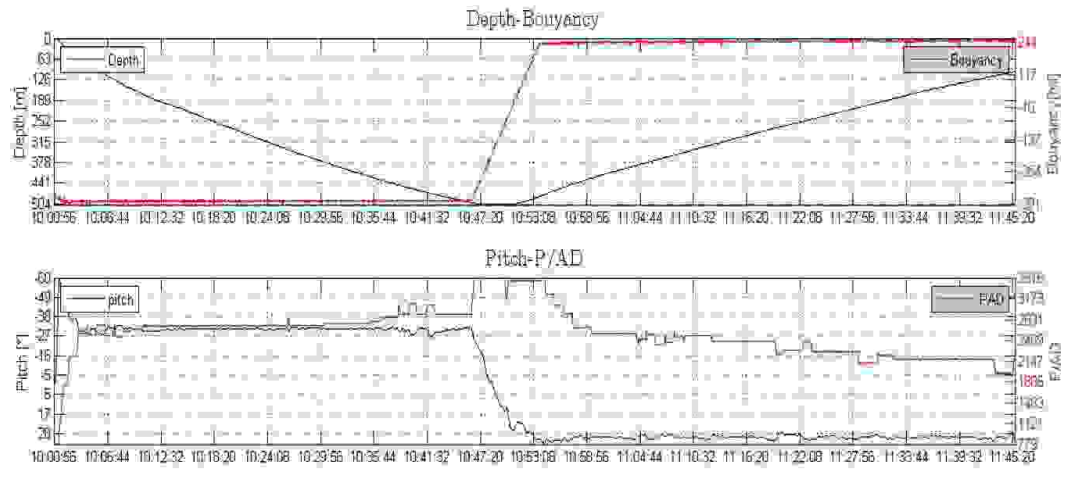

Group 2:

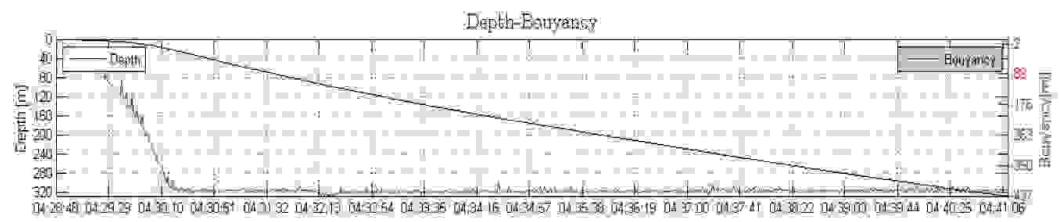

Pitrde-P/AD
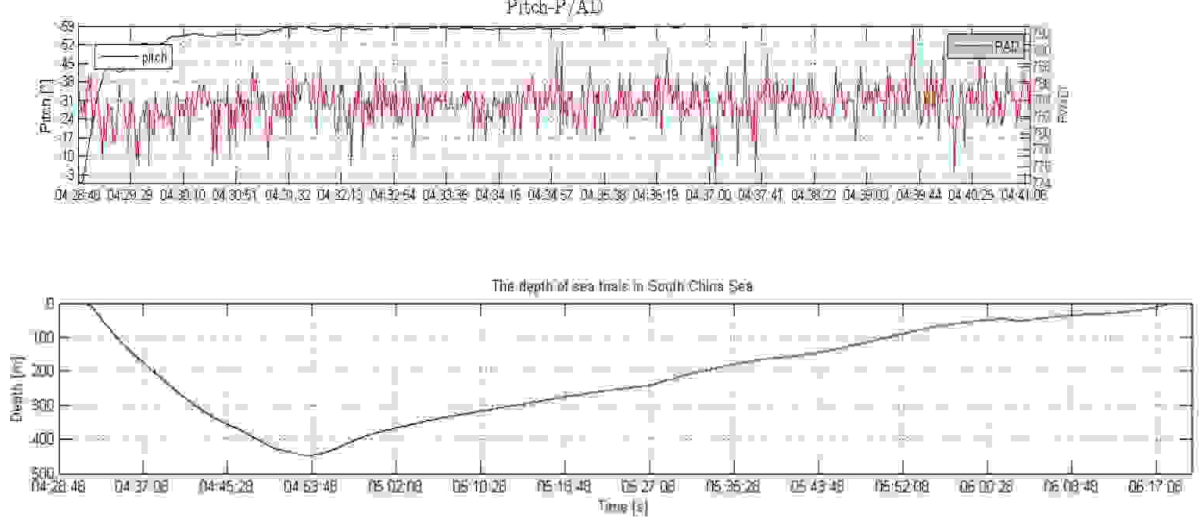

Figure 15: Pitch angle of the glider (black line) and battery position (red line) during tests in the South China Sea. 
We analyzed the two group data. From the first group we knew the maximum depth was 504.6m and the second group maximum depth was $450.1 \mathrm{~m}$. We would like the reason that the profile data of second group was not complete. Because the data of profile was written into the first TF card (256 MB), but the TF card was full during this profile. Thus we used the data of CTD in the second TF card to certify that the profile was finished. The first group set values were $30^{\circ}\left(-30^{\circ}\right.$ at diving into water and $30^{\circ}$ at floating out of water). We obtained the steady-error was $0.9^{\circ}$ during the diving time and $1.2^{\circ}$ during the floating time. One of the settling times was $46 \mathrm{~s}$ when the angle changed from $-60^{\circ}$ to $-30^{\circ}$ and the other was $97 \mathrm{~s}$ when the angle changed from $-30^{\circ}$ to $30^{\circ}$. The overshoot of diving time was $2.4^{\circ}$ and $0.3^{\circ}$ at floating time. The second group set values were $60^{\circ}\left(-60^{\circ}\right.$ at diving into water and $60^{\circ}$ at floating out of water). We obtained a part profile data and the steady-error was $0.9^{\circ}$ and the overshoot was $0^{\circ}$ during the diving time. The settling time was $164 \mathrm{~s}$ when the angle changed from $0^{\circ}$ to $-60^{\circ}$. From this group data, the settling time was abnormal. The pitch angle kept $54^{\circ}$ for 70 s but the adjustable battery was moving all the time. So we thought there might be some effect form the ocean current for big angle during this depth region.

We compared the results form each group of the lake and sea trials at Table 4.

Table 4: Pitch angle analysis.

\begin{tabular}{ccccccc}
\hline & $\begin{array}{c}\text { Initial } \\
\text { value }\left({ }^{\circ}\right)\end{array}$ & $\begin{array}{c}\text { Set } \\
\text { value }\left({ }^{\circ}\right)\end{array}$ & $\begin{array}{c}\text { Final } \\
\text { value }\left({ }^{\circ}\right)\end{array}$ & $\begin{array}{c}\text { Settling } \\
\text { time(S) }\end{array}$ & $\begin{array}{c}\text { Maximum } \\
\text { overshoot }\left({ }^{\circ}\right)\end{array}$ & $\begin{array}{c}\text { Steady-state } \\
\text { error }\left(^{\circ}\right)\end{array}$ \\
\hline Lake trial & -46 & -30 & -31.8 & 43 & 0 & 1.8 \\
(diving state) & -46 & -30 & -32.2 & 42 & 0 & 2.2 \\
& -45 & -30 & -31.9 & 45 & 0 & 1.9 \\
\hline \multirow{2}{*}{ Lake trial } & 45 & 30 & 30.8 & 24 & 0 & 0.8 \\
(floating state) & 45 & 30 & 30.9 & 29 & 0 & 0.9 \\
\hline Sea trial & 45 & 30 & 31.0 & 23 & 0 & 1.0 \\
(diving state) & -60 & -30 & -29.2 & 46 & 2.4 & 0.8 \\
\hline Sea trial & -30 & -60 & -59.1 & 164 & 0 & 0.9 \\
(floating state) & & 30 & 28.8 & 97 & 0.3 & 1.2 \\
\hline
\end{tabular}

From Table 4, we got nine groups valid data. No overshoot was observed in the lake trials and the overshoot of sea trials was small. The maximum overshoot was $2.4^{\circ}$ less than $10^{\circ}$ of PID control. The settling time reached the control index. There was some steady-state error in the lake trial due to the infeasible control strategy when the angle change was about $15^{\circ}$. Once we changed the control strategy, the steady-state error was decrease to about $1^{\circ}$ when the angle change was $60^{\circ}$. We found the buoyancy and ocean current could bring negative effect to the pitch control. Internal ocean waves might also have had a negative influence on the pitch angle. Compared with the classical PID and LQR [12] control results, this control algorithm was more effective.

\section{Conclusions}

We finished some valuable work in this paper. At first, we established the motion model of glider and proposed the formula of pitch angle. Then, a system identification method was used to identify the transfer function based on the time-domain equation and earlier experimental data. A fuzzy-PID algorithm was developed for controlling the pitch angle of an underwater glider. The Fuzzy-PID control algorithm was used to design the controller. Fuzzy rules were established first. Then, the degree of membership was determined. Using the MATLAB Simulink toolbox, the control system diagram was established. This could control the pitch angle by adjusting three parameters $(K p, K i$, and $K d)$ on-line. In the lake and sea trials, the minimum overshoot reached $0 \%$, the settling time was about $34 \mathrm{~s}$ when the change in the angle was $15^{\circ}$, and the minimum steady-state error was $0.8^{\circ}$. It certified this control 
algorithm was effective. However, we ignored the negative effect of buoyancy and ocean current or internal waves. In future, we will improve our mathematical model added the buoyancy and optimize our controller to against the ocean current. Then we will apply this kind of control mode to control the roll angle, heading angle and optimizing the motion trajectory.

\section{Acknowledgment}

This work has been supported by the Underwater Glider Research Center of Ocean University of China, 863 Plan Acoustic Glider System Development Team. (Grant Number: 2012AA091004).

\section{References}

[1] A. J. H. Al Gizi, M. W. Mustafaa, H. H. Jebur, A novel design of high-sensitive fuzzy PID controller, Appl. Soft Comput., 24 (2014), 794-805. 1

[2] B. M. Al-Hadithi, A. Jiménez, R. G. López, Fuzzy optimal control using generalized TakagiSugeno model for multivariable nonlinear systems, Appl. Soft Comput., 30 (2015), 205-213. 1

[3] P. Dash, L. C. Saikia, N. Sinha, Automatic generation control of multi area thermal system using Bat algorithm optimized PDPID cascade controller, Int. J. Electr. Power Electron. Power Syst., 68 (2015), 364-372. 1

[4] R. E. Davis, C. C. Eriksen, C. P. Jones, Autonomous buoyancy-driven underwater gliders, Technol. Appl, Auton, Underwater Vehicles, (2002), 37-58. 1

[5] C. C. Eriksen, T. J. Osse, R. D. Light, T. Wen, T. W. Lehman, P. L. Sabin, J. W. Ballard, Seaglider: a long-range autonomous underwater vehicle for oceanographic research, IEEE J. Oceanic Eng., 26 (2001), 424-436. 1

[6] B. B. Ghosh, B. K. Sarkar, R. Saha, Realtime performance analysis of different combinations of fuzzyPID and bias controllers for a two degree of freedom electrohydraulic parallel manipulator, Robot. Comput. Int. Manuf., 34 (2015), 62-69. 1

[7] N. A. A. Hussain, M. R. Arshad, R. M. Mokhtar, Underwater glider modelling and analysis for net buoyancy, depth and pitch angle control, Ocean Eng., 38 (2011), 1782-1791. 2.1.4

[8] K. Isa, M. R. Arshad, Buoyancy-driven underwater glider modelling and analysis of motion control, Indian J. Geo-Marine Sci., 41 (2012), 516-526. 1

[9] K. Isa, M. R. Arshad, Modeling and motion control of a hybrid-driven Uunderwater glider, Indian J. Geo-Marine Sci., 42 (2013), 971-979. 1

[10] K. Isa, M. R. Arshad, S. Ishak, A hybrid-driven underwater glider model, hydrodynamics estimation, and an analysis of the motion control, Ocean Eng., 81 (2014), 111-129. 1

[11] N. E. Leonard, J. G. Graver, Model-based feedback control of autonomous underwater gliders, IEEE J. Oceanic Engi., 26 (2001), 633-644. 1

[12] M. M. Noh, M. R. Arshad, R. M. Mokhtar, Depth and pitch control of USM underwater glider: performance comparison PID vs. LQR, Indian J. Geo-Marine Sci., 40 (2011), 200-206. 1, 3.2.2

[13] D. Pan, F. Gao, Y.-J. Miao, R. Cao, Co-simulation research of a novel exoskeleton-human robot system on humanoid gaits with fuzzy-PID/PID algorithms, Adv. Eng. Softw., 79 (2015), 36-46. 1

[14] K. Premkumar, B. V. Manikandan, Fuzzy PID supervised online ANFIS based speed controller for brushless DC motor, Neurocomputing, 157 (2015), 76-90. 1

[15] R. K. Sahu, S. Panda, P. C. Pradhan, Design and analysis of hybrid firefly algorithm-pattern search based fuzzy PID controller for LFC of multi area power systems, Int. J. Electr. Power Electron. Power Syst., 69 (2015), 200-212. 1

[16] B. K. Sahu, S. Pati, P. K. Mohanty, S. Panda, Teachinglearning based optimization algorithm based fuzzy-PID controller for automatic generation control of multi-area power system, Appl. Soft Comput., 27 (2015), 240-249. 1

[17] D. C. Seo, G. Jo, H. S. Choi, Pitching control simulations of an underwater glider using CFD analysis, OCEANS 2008MTS/IEEE Kobe Techno-Ocean, (2008), 1-5. 1

[18] J. Sherman, R. E. Davis, W. B. Owens, J. Valdes, The autonomous underwater glider "Spray", IEEE J. Oceanic Eng., 26(2001), 437-446. 1

[19] H. Yousef, Adaptive fuzzy logic load frequency control of multi-area power system, Int. J. Electr. Power Electron. Power Syst., 68 (2015), 384-395. 1

[20] S.-W. Zhang, J.-C. Yu, A.-Q. Zhang, F.-M. Zhang, Spiraling motion of underwater gliders: Modeling, analysis, and experimental results, Ocean Eng., 60 (2013), 1-13. 2.1.1

[21] T. Zhao, J. Xiao, A new interval type-2 fuzzy controller for stabilization of interval type-2 TS fuzzy systems, J. Franklin Inst., 352 (2015), 1627-1648. 1 